\title{
Study of Electrochemical Properties of Tibernaemontana Divaricata as a Non-Conventional Power Source
}

\author{
KAVITA E SHETE, SHADAF I ATTAR and PRAMOD S KULKARNI*
}

Dept. Chemistry, Hutatma Rajguru Mahavidyalaya, Rajgurunagar, Pune-410505(MS), India pramodskulkarni3@gmail.com

Received 14 January 2014 / Accepted 24 January 2014

\begin{abstract}
A biochemical property of Tibernaemontana divaricata plant leaves has been used to develop the renewable bioelectrical energy sources for micropower electronic devices and they are termed as bio-emf devices (BEDs). The unusual information of the bio-electro devices using leaves of ornamental importance and medicinal plant from the family Apocynaceae viz. Tibernaemontana divaricate has been studied. The qualitative aspects of the leaves to build up renewable bioelectrochemical low power sources have been attempted. In this experiment the qualitative results indicates the feasible involvement of bio-activities in the operational device of bio-emf devices.
\end{abstract}

Keywords: Non-conventional energy, Bioelectrical energy sources, Bio-emf devices, Apocynaceae, Tibernaemontana divaricata, Low power sources

\section{Introduction}

The energy sources are of two types, non-conventional energy and conventional sources. Sources for the non-renewable energy is earth, these sources are widely available and affordable. Since the continuous and heavy utilization of these sources, their price is continuously increasing and shortage may occur in future. Due to heavy utilization of Nonrenewable sources continues to rise producing high levels of carbon dioxide which is a major cause of global warming. Due to shortages, increasing prices and environmental problems, therefore, their scope to generate alternative energy sources like renewable sources.

Non-conventional energy that comes from resources which are continually replenished on a human time scale. Wind, rain, waves and geothermal heat, sun and bioenergy are example of non-conventional energy sources and these sources are sustainable, therefore, will never run out but these energy sources do not generate the sufficient quantity of electricity that are produced by the traditional non-renewable sources.

An electric battery is the one form of non-conventional energy sources which convert chemical energy into electrical energy with the help of one or more electrochemical cells example lead-acid, Ni-Cd battery etc. The chemical battery has various disadvantages such as toxic, corrosion of electrodes and sometimes causes explosion, to overcome these problems many scientists study on the use of biological materials to make the biobatteries 
and these batteries are different from existing batteries ${ }^{1-4}$. Various studies on these cells reveal that there are two main contributions in energy generations from biocells ${ }^{5}$. Biological contributions may be increased by the proper selection of the leaf, while voltaic contributions may be increased by the selection of proper metals. As non-renewable energy sources are falling day by day. It is essential to replace the deficiency. This is an attempt made to generate power through biological means and this biocell is one such nonconventional energy source. It will meet out the power deficiency in the future.

The various plant parts like leaves are natural biosystem which contain different organic and inorganic ions. The controlled and regulated ionic motion in plants makes the biosystem different from a usual physical and electrolytic system. Hence, the plant parts may be called as "bioelectrolytic systems" or "bioenergy conducting systems". Ionic conductor is a prerequisite condition for an electric material. Ionic condition found within the living systems has great importance in low power energy sources. Hence we thought of exploring the possibility of using the plant leaves as a new non-conventional matter for developing low power sources for micro-electronic devices i.e. small technological object or instrument.

Herein we present results on the development and characteristics of Bio-electro devices using leaves of Tibernaemontana divaricate. Tibernaemontana divaricata belongs to Apocynaceae family which have ornamental and ayurvedic medicinal importance. In this paper we study, variations of emf with time and temperature.

\section{Experimental}

The bio-emf cell incorporates an anode made up of copper metal and cathode made up of zinc metal with the same dimension as anode were purchased from the market. Tibernaemontana divaricata leaves are collected from Rajgurunagar village, Pune (Inida) and collected leaves were dried in shade and grinded with distilled water. The mixture has been taken as electrolyte.

\section{Results and Discussion}

The curshed Tibernaemontana divaricata leaf acted as a good electrolyte and copper and zinc metals acted as positive and negative electrodes respectively. We studied experiments with variations of potential using Tibernaemontana divaricata leaf with respect to time and temperatue and current with time, under open circuit condition.

\section{Variation of potential with time}

The results of bioelectro devices under open circuit conditions for potential variations with time are given in Table 1 and Figure 1.

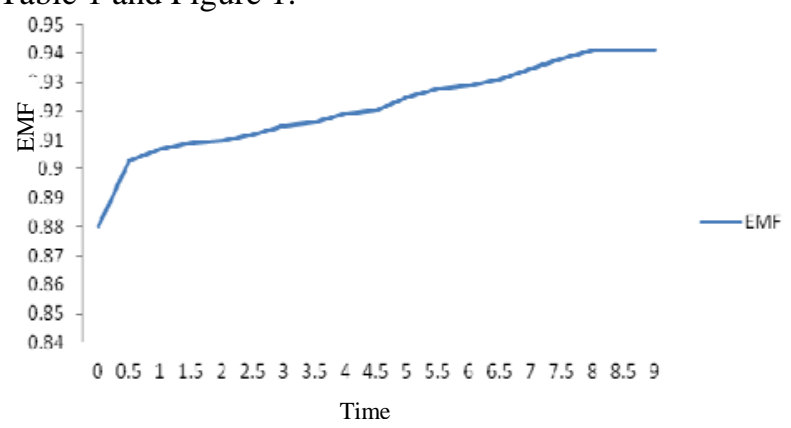

Figure 1. Variation of EMF with time period of bioelectro devices for Tibernaemontana divaricata (under open circuit condition) 
Table 1. Results of bioelectro device for voltage and time for biofluids of Tibernaemontana divaricata (under open circuit condition)

\begin{tabular}{ccc}
\hline Entry & Time, min & Voltage, V \\
\hline 1 & 0.0 & 0.880 \\
2 & 0.5 & 0.903 \\
3 & 1.0 & 0.907 \\
4 & 1.5 & 0.909 \\
5 & 2.0 & 0.911 \\
6 & 2.5 & 0.912 \\
7 & 3.0 & 0.915 \\
8 & 3.5 & 0.916 \\
9 & 4.0 & 0.919 \\
10 & 4.5 & 0.921 \\
11 & 5.0 & 0.925 \\
12 & 5.5 & 0.928 \\
13 & 6.0 & 0.929 \\
14 & 6.5 & 0.931 \\
15 & 7.0 & 0.935 \\
16 & 7.5 & 0.938 \\
17 & 8.0 & 0.940 \\
18 & 8.5 & 0.941 \\
19 & 9.0 & 0.941 \\
\hline
\end{tabular}

The bioelectro devices gave initial value of as $0.880 \mathrm{~V}$, at temperature $28{ }^{\circ} \mathrm{C}$ and Table 1 shows emf changes with time and overall trend shows it increases with time. It have been noted that its value is even larger than the initial value. The potential change is bio-originated. The electrolytes, oxidants and reductants present in plant organs, which contribute in the complex biochemical reactions responsible for variations of potential.

\section{Variation of potential with temperature}

Next we study, the effect of temperature on potential of bioelectro devices under open circuit condition. The initial value 0.880 at $28{ }^{\circ} \mathrm{C}$ and we changes temperature from $28{ }^{\circ} \mathrm{C}$ to $25^{\circ} \mathrm{C}$ and $31^{\circ} \mathrm{C}$. Effect of temperature on potential as shown in Table 2 and table shows potential is directly proportional to temperature (Figure 2).

Table 2. Results of bioelectro device for voltage and temperature for biofluids of Tibernaemontana divaricata (under open circuit condition)

\begin{tabular}{ccc}
\hline Entry & Temperature, ${ }^{\circ} \mathrm{C}$ & Voltage, $\mathrm{V}$ \\
\hline 1 & 25 & 0.876 \\
2 & 28 & 0.880 \\
3 & 31 & 0.883 \\
4 & 34 & 0.886 \\
\hline
\end{tabular}




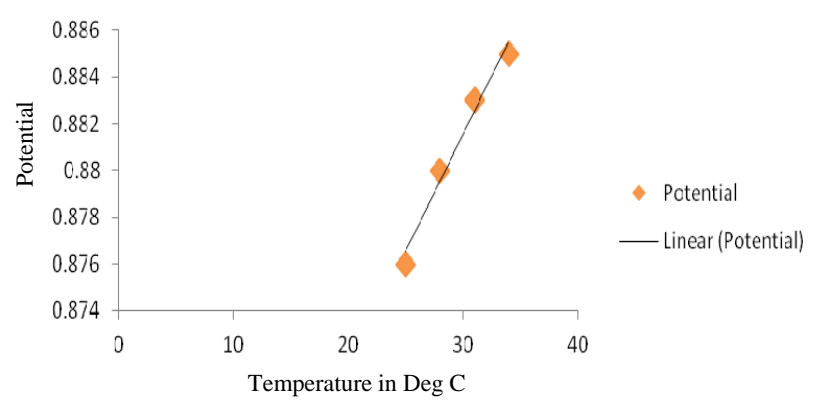

Figure 2. Variation of EMF with temperature of bio-electro devices for Tibernaemontana divaricata (under open circuit condition)

\section{Conclusion}

- The bioelectrochemical cell is primary cell.

- Here power is generated from plant source on voltaic cell.

- This is the best alternative to electricity which reduces cost and pollution.

- It generates economic sources for farmers as well as electricity in an emergency.

\section{References}

1. Jain K, Hundet A A, Abragham S and Nigam H L, Sansevieria Trifacciata Bull Electrochem., 1987, 3, 359-361.

2. $\quad$ Jain K M and Abragham S, Pakistan J Sci Indl Res., 1988, 31, 803-806.

3. Jain K M and Hundet A, Pakistan J Sci Ind Res., 1988, 31, 690-692.

4. Jain K M, Abragham S and Hundet A. Japan J Appl Phy., 1988, 27, 867-868.

5. Ramalingam S, Prabhu T, Mani Maran K, Murugan S and Nagarajan S M, Asian J Microbiol Biotech Env Sci., 2009, 11(4), 783-784. 